\title{
Effective Reading Comprehension in EFL Contexts: Individual and Collaborative Concept Mapping Strategies
}

\author{
Zahra Riahi (Corresponding author) \\ IAU Research and Science Center, Khouzestan Branch, Iran \\ E-mail: riahi_z@yahoo.com
}

Natasha Pourdana

Faculty of Literature and Foreign Languages, ELT Department of Higher Education, Islamic Azad University, Karaj Branch, Iran E-mail: Natasha.qale@gmail.com

Doi:10.7575/aiac.alls.v.8n.1p.51

URL: http://dx.doi.org/10.7575/aiac.alls.v.8n.1p.51
Received: 09/09/2016

Accepted: 16/12/2016

\begin{abstract}
The present study attempted to investigate the possible impacts of Individual Concept Mapping (ICM) and Collaborative Concept Mapping (CCM) strategies on Iranian EFL learners' reading comprehension. For this purpose, 90 pre-intermediate female language learners ranged between 12 to 17 years of age were selected to randomly assign into ICM, CCM and Control groups in this study. After taking Key English Test (KET), the ICM and CCM groups received EFL reading materials presented and practiced with ICM and CCM strategies, respectively, while the Control group received only conventional instructions to reading comprehension. After conducting the treatment, all participants took a Concept Mapping post-test constructed by the researchers. The hypothetical assumptions in this study were in favor of ICM and CCM strategies to improve the Iranian EFL learners' reading comprehension. Statistics supported the outperformance of the ICM and CCM groups comparing to Control group who received convention PPP teaching techniques on Concept Mapping post-test. However, the superiority of neither strategies was statistically proved so that no meaningful difference between the reading comprehension of the ICM and CCM groups were detected. Therefore, the researchers failed to determine which strategy caused a better or higher impact. Some pedagogical implications and recommended topics for further research were provided to the motivated researchers.
\end{abstract}

Keywords: Collaborative concept mapping, individual concept mapping, reading comprehension, EFL, cooperative learning

\section{Introduction}

Reading is perhaps the most important language skill in our modern life. It helps people to learn new knowledge and experience the world everywhere at any time. "People usually read because they want to obtain specific information about a specific subject", as Farhady (2005) asserted, or as Shankar (2008) underlined, "theories about reading and its teaching techniques represent the influence reading has on listening, speaking, writing, and even translating". The significance of reading becomes yet more identifiable when it comes to reading in a foreign or second language for academic aims or in academic contexts (Carrell, 1983; Day \& Bamford, 2002). Likewise, Eskey (2005) maintained that in the EFL setting, reading might be the most essential language skill to be learned, since most learners of English might not really need to talk or listen to the speakers of English in their day-to-day lives, but would definitely need to read in that language for different reasons.

Bunner believed (2002) that reading comprehension is the capability to interact with words and ideas on the page in order to understand what the writer has to write. It includes meaningful interpretation of written language. It involves an interaction of the reader, the text and the situation in which the text is read. Shaw (1959) underlined, "reading is considering with the author and getting his ideas. Reading involves re-creating the experience and thought of the writer, making images produced by the printed letters, and increasing one's vocabulary. It needs organizing and retaining ideas and impressions gained from the printed page". Rauch and Weinstein (1968) demonstrated that reading involves more than the capability to identify and pronounce words correctly; it involves the reader's knowledge of language, processing of messages the text carries, his guessing power, as well as his psychomotor movements, emotional response and perception. In addition to the complexity of reading in a foreign language context, its process is so far more cognitively demanding that the language learners need to coordinate their attention, perception, memory, and comprehension.

According to Brown (2007), teachers occasionally have a reason to ask their students to read aloud. Oral reading can serve as (a) an evaluative check on bottom-up processing skills, (b) a pronunciation check and (c) an extra class participation if the teacher intends to highlight a short part of a reading text. However, there are some disadvantages to 
overemphasis on oral reading, such as lack of authenticity, low attention to the reading content and its false interpretation as an active contribution of the reader in the learning process. On the other extreme, silent reading is mostly called for intensive and involved reading. Intensive reading can focus learners' attention to certain grammatical forms, discourse markers, and other surface structural details for the aim of comprehending literal meaning, text implications, rhetorical relationship, and the like (Brown, 2007). According to Nuttall (1996), the major aim of intensive reading is to arrive at an understanding not only of what the text means but also of how the meaning is produced. The 'how' is as important as the 'what', for the intensive lesson is intended primarily to train strategies which the student can go on to use with similar texts. Nuttal also stated that intensive reading is immensely impressive for developing the reading skills in learners since most reading skills are trained by reading short texts in details.

\section{Review of Related Literature}

Among the influential factors in reading comprehension especially in foreign language contexts, reading strategies enable effective readers to reach their reading goals. Learners' strategies, as one of the most important types of strategies, are specific attacks that learners make to different comprehension problems when receiving input or producing output (Rashtchi \& Keyvanfar, 2010). Park proposed (1995) his definition of learning strategies as "the mental activities that people use when they study, to help themselves acquire, organize, or remember incoming knowledge more efficiently". In 1985, O'Malley et al classified learning strategies under three groups:

(1) Metacognitive strategies, such as planning for learning, thinking about the learning process as it is taking place, monitoring one's production or comprehension, and evaluating learning after an activity is completed,

(2) Cognitive strategies, such as repeating, translating, grouping, note taking, deducting using, imagery, auditory representation, key word, contextualization, elaboration, transfer, and

(3) Socio-affective strategies, such associal-mediating activity and transacting with others.

O'Malley et al (1985) emphasized that language learners without metacognitive strategies have no direction or ability to monitor their own progress, accomplishments, or their future learning. Among these strategies, metacognitive strategies are assumed as the most important in developing students' language skills, too (Anderson, 1991).

A certain number of metacognitive and cognitive learning strategies characterize most sophisticated and successful language learners. These strategies include mind mapping, concept mapping, identifying key information and note taking (Weinstein, 1988). Concept maps have been defined as those metacognitive strategies that persuade learners to think reflectively about what they know through the visual representation of conceptual meanings and relationships (Mintzes, Wandersee \& Novak, 1998). The process of constructing and modifying a concept map involves making decisions about different ways the concepts are related to one another, leading the individuals to reflect on their prior knowledge as it relates to new material and to engage in controlling processes of planning, monitoring progress, and assessing goal attainment as the map is being constructed (Brown, 1987).

Concept mapping as a strategy for better and deeper understanding has four key functions:

(a) elaboration that allows the previously acquired knowledge to relate to the new information in order to determine the main ideas and their relationship with other supporting ideas,

(b) reduction that identifies and retains the central idea to form a global scheme,

(c) coherence that favors the construction of a coherent information structure so that it can be used to identify the ruptures in textual coherence, and

(d) metacognition that favors the detection and repairs of bias and gaps that may appear in the process of comprehension (Hilbert \& Renkl, 2008).

According to Boyle (1997), “ the main aim of applying concept maps is more to make effective learning rather than to facilitate learning. This thought emanates from the belief that learning happens during the applying concepts and relating them to each other. Since the use of concept maps involves strategies like symbolizing, cataloguing, structuring and visualizing, they can assist learners construct their own conceptual structures of any scientific phenomena. The substantial benefit of concept mapping is its relational objective. Concept maps enable the associations to be made among relevant concepts. In the educational context, it is claimed that meaningful learning takes place by linking new concepts to existing the knowledge (Craik \& Lockhart, 1972). Fraser (1993: 398) proposed four principles for constructing concept maps:

(a) Concepts are put in geometric forms or rectangles. They can be showed by key words, simple drawings or phrases. Lines or arcs utilized to link the concepts. Sometimes linking words are written on the arcs to characterize the relationship between the two concepts.

(b) The linking words should illuminate the relations between the two concepts. Together with the two concepts, the linking words form a proposition - like "the grass is green" from the concepts "grass", "green", and the linking word "is".

(c) No right or wrong map exists, as all maps are idiosyncratic to each individual. Various persons may draw different maps for the same conceptual domain. A concept map can be wrong, however, if propositions are inaccurate, such as "the bear speaks English".

(d) The interconnections between concepts give rise to the power of the concept map. More 
interconnectionsand cross-linkages are an indication of a greater complexity and sophistication of understanding.

Novak and Canas (2006) emphasized that in constructing a concept map, it is important to begin with a domain (an area) of knowledge that is familiar to the person constructing the map. Since concept map structures are dependent on the context in which they will be used, it is best to identify a segment in a text, a laboratory activity, or a particular problem or question that one is trying to understand. This creates a context that will help to determine the hierarchical structure of the concept map. It is also helpful to select a limited domain of knowledge for the initial concept maps. Once a domain is selected, the next step is to identify the key concepts that apply to that domain. They can be listed to establish a rank order from the most general and most inclusive concepts to the most specific, least general concepts. Although this rank order can be approximate, it helps to begin the process of map construction. The next step is to construct a preliminary concept map. It can be done by writing all the concepts on Post-its or using a computer software. Post-it stickers allow groups of students to work on a whiteboard or butcher paper and to move the concepts around easily. This is necessary as one begins to struggle with the process of building a good hierarchical organization.

Evidently, concept mapping strategies in the planning phase of reading comprehension have positive effects on the students' successful task performance. They motivate ingenuity, activate prior knowledge, organize the students' existing words and concepts, give the main points of the text, evaluate their readiness for the task, persuade the interaction with others, stimulate their interest to sustain on task and finally boost their language production (Novak \&Canas, 2006). Recently, a study by Liu, Chen and Chang (2010) emphasizes the impacts of computer-assisted concept mapping on EFL learners' English reading comprehension at college levels. They performed a study with 192 freshmen who were divided into low and high level groups in order to their English language proficiency. They were assigned as experimental and Control groups. The treatment was performed in ten weeks, two hours a week. The participants took four tests in reading comprehension: a pre-test (before the experimental teaching), Test 1 (after the first practice of concept mapping was completed), Test 2 (after the second practice of concept mapping), and Test 3 (after their third concept map practice). The scholars concluded that concept mapping reading strategy is more effective than the conventional reading strategies to improve less skillful readers' comprehension and narrow the reading proficiency gap between the high achiever and low achiever readers.

Novak and Gowin (1984) elaborated on the valuable impacts of concept mapping reading strategy on EFL learners' reading comprehension relying on its impact on visualizing the relationship among concepts. Concept mapping lets the students to analyze language structures, classify ideas into groups, obtain the main ideas' text according to find out the reading passages. In concept mapping method, the students are required to determine sub-concepts, categorize and arrange them, connect related sub-concepts, make new cross-links, link old information in one's prior knowledge with the new information, and give examples to interpret the map. This process can improve understanding and decrease reading difficulties by contributing readers apply higher level reading strategies.

Concept mapping can be used as an individual (ICM) or collaborative (CCM) learning strategies. Initially, it may be more effective if the teacher demonstrates the development of a concept map from raw data and asks her students as a collaborative group to make links, associations, and conclusions while emphasizing the dynamic nature of the concept map. Collaborative Concept Mapping (CCM) strategy is defined as a process where two or more individuals are engaged in coordinated and sustained efforts to create one or more concept maps in order to learn and construct knowledge (Gao, 2013). In the past decade, several studies have documented the benefits of Individual Concept Mapping (ICM) strategy, too. These studies would support the fact that concept mapping can serve as an instructional tool to promote individuals' conceptual understanding (Herl et al., 1999) and to assist reflective instructions (Mason, 1992). ICM strategy has been recognized to be essential element in enhancing learning and students' attitudes toward the course subject matter (Horton et al., 1993). According to Broggy (2009), an individual concept map is a visual representation of a student's knowledge structure on a particular topic as constructed by himself. In addition, he stated that ICM brings in light the individual differences in learning as different people usually generate different concept maps even on the same subject area. Each individual concept map is unique due to each person's own experience.

One apparent difference between ICM and CCM strategy is that the latter triggers a sense of community and rapport among the students. In ICM context, learners are seldom allowed communicate with other fellow students (Gao, 2007). According to Van Boxtel et al. (2002), "applying collaborative concept maps would persuade learners to engage in two kinds of actions that are central to learning and understanding: elaborative actions, and negotiation of meanings. Firstly, the CCM strategy suggests various opportunities to generate interactions that enhance the development of knowledge. For example, it would increase the amount of shared information, presenting it visually, in a concrete and concise manner. The collaborative concept mapping strategy persuade learners to identify the concepts presented in the text, exchange the meanings they attach to these concepts and explicit the relationships between these ideas. Secondly, CCM strategy raises the right situations to converse shared knowledge where learners are not only compelled to reflect and develop their own knowledge but also require to develop their teammates, consider and integrate their ideas". Novak (2002) stated that collaborative concept maps are excellent tools for cooperative activity that will lead to a successful and meaningful learning.

Okebukola and Ogunniyi (1984) studied the two language learning modes of cooperative or individualistic under concept mapping strategy. The objective of their study was to compare the relative achievement in using ICM and CCM strategies. They found out that the cooperative mode of concept mapping significantly improved the students' misconceptions and doubts more than individualistic map practices. On the other hand, Van Boxtel et al. (1997) 
compared the learning outcomes emergent from collaborative concept mapping and collaborative poster designing, collaborative construction of conceptual understanding and interaction processes. They described ICM as a more suitable technique for classroom engagement than CCM. Inspired by the controversy existed in the literature on the effectiveness of ICM or CCM strategies, this quasi-experimental research aimed to investigate the comparative effects of ICM and CCM on Iranian EFL learners' reading comprehension in an EFL context wherein the majority of language teaching techniques fail to sustain the EFL learners' ongoing success in their language learning achievement.

\section{Method}

\subsection{Participants}

The participants in this research were 90 Iranian female EFL learners at the intermediate level of English proficiency, studying at a private language school in Karaj, Iran in 2015. Their age ranged between 12 to 17 years old. The researchers assigned the research sample into three intact groups after administering Key English Test (KET) as the pretest in this research. The experiment lasted fourteen 90 minute sessions. The two experimental groups practiced reading English passages with either individual concept mapping (ICM) or collaborative concept mapping (CCM) strategies, while the Control group received the researchers' conventional teaching of English passages and comprehension questions as the post-reading activities.

\subsection{Instruments and Materials}

\subsubsection{Key English Test (KET)}

All grouped participants participated in a KET (The Cronbach's alpha index of reliability of the KET was .761) as the pretest in this study in order to make sure there was no meaningful difference among the three groups before receiving the treatment and to make sure that the participants were at the same level of language proficiency.

\subsubsection{Read Theory Website}

The reading passages in this study were selected online from the Read Theory Website. Read Theory (http://www.readtheory.org) is a powerful online English resource that offers a wide range of reading passages and activities for EFL students in wide age ranges and proficiency levels. The designed material in this website can easily be implemented in the language classrooms to support reading, writing, and critical thinking skills. This website provides high quality, engaging contents, designed to assist self-learning and critical thinking, outlined by national benchmarks and specified by the Common Core State Standards (CCSS).

The reading assessment at this website represents one of the best available resources in reading comprehension. The content of the Read Theory (over 1,000 reading comprehension passages and comprehension check questions) is broken down evenly across the twelve graded levels, allocating every level just under 100 quizzes in total.

Since this online program matched to this research participants' level of language proficiency, it was likely that they were well-served with a varying range of complexity, being encouraged to journey away from their comfort zone of ordinary language classroom. The content of the selected reading passages included a wide range of mock itineraries, imaginary movie reviews, argumentative essays, informative passages, research reports, newspaper articles, and even more. The readability of the selected passages was calculated online in http://www.readabilityformulas.com/fleschgrade-level-readability-formula.php following The Flesch Grade Level Readability Formula. Accordingly, the passages with readability range of 7 to 8 was considered as suitable for EFL learners as intermediate level, hence they were selected.

\subsection{Procedure}

In the pre-reading phase, both ICM and CCM groups received the basic instructions on concept mapping strategies. Presenting the selected concept map strategies was according to the Oxford's procedure for strategy instruction (1990). The procedure consisted of five stages as following:

(1) Describing ICM and CCM strategies,

(2) Discussing goals and objectives for reading passages,

(3) Modeling the strategies,

(4) Monitoring students' mastery of strategy, and

(5) Guiding practice and feedback.

A step-by-step instruction for creating a concept map was illustrated and modeled through creating a map while students were offered several topics to choose for their first concept map activity. Once the group agreed upon a topic, it was written on the whiteboard. The topic was labeled as the main idea in the concept map. The possible subtopics were generated afterward. Gradually, the researchers used arrows to link main ideas together and to demonstrate the subtopics. The students took part in the process by brainstorming over the possible details and categories. They were coached how to write subtopic information in phrasal structures. Phrasal language forms were modeled and elaborated. The learners helped in generating ideas to be located inside the map bubbles. Upon completion of the map, the researchers modeled the transfer of input into subtopic information in the map. Instructions followed the hierarchical sequence of transferring input into concept maps, starting with top-level structures (i.e. topics and subtopics). The categories, including the main and supporting ideas were reviewed later. The researchers sketched how they can rewrite 
the information from oral or written form (including topic sentences and supporting sentences) into the bubbles.

In CCM group, participants collaborated in small groups. After reading every text, they worked together on understanding the organizational structure of the text to complete in the bubbles in the concept map framework. The researchers monitored the participants during the group work tasks and gave them feedback upon their demands. In ICM group, learners were asked to read the passages before highlighting the main ideas in the passage and filling in the bubbles. All activities were performed individually and learners were reminded not to cooperate with one another. Teaching the passages for the Control group followed the conventional method of presentation and practice. Before reading the text, the researchers raised some questions on the text topic. Later, they were presented with the new words in the passage. After reading the text, participants were required to answer the post-reading multiple-choice items.

All participants in ICM, CCM and Control groups took a Concept Map post-test constructed by the researchers. Participants were required to read three short passages and complete 28 numbered bubbles inside the concept maps. There was a three-choice item followed every bubble in the map. Since precise scoring was easily possible with multiple-choice items, the post-test was considered as objective and reliable account of the participants' performance on reading comprehension and concept map tasks. Every correct answer was counted as one and every incorrect answer as zero.

\section{Results}

The scores of ICM, CCM and Control groups on Key English Test (KET) as the pre-test were descriptively analyzed for measures of range, mean, standard deviation and skewness.

Table 1. Descriptive Statistics for KET

\begin{tabular}{|c|c|c|c|c|c|c|c|}
\hline Group & $\mathrm{N}$ & Min & Max & Mean & Std. Deviation & Std. Error & Skewness \\
\hline $\mathrm{ICM}$ & 30 & 10.00 & 34.00 & 23.60 & 6.25 & 1.14 & -.362 \\
\hline $\mathrm{CCM}$ & 30 & 10.00 & 34.00 & 24.83 & 6.45 & 1.17 & -.367 \\
\hline Control & 30 & 10.00 & 35.00 & 24.13 & 6.84 & 1.25 & -.290 \\
\hline
\end{tabular}

Similarly, the scores of ICM, CCM and Control groups on Concept Map multiple choice post-test were descriptively analyzed.

Table 2. Concept Map multiple choice test

\begin{tabular}{lllllclc}
\hline Group & $\mathrm{N}$ & Min & Max & Mean & Std. Deviation & Std. Error & Skewness \\
\hline ICM & 30 & 17.00 & 27.00 & 23.16 & 3.13 & 0.57 & -.488 \\
CCM & 30 & 17.00 & 27.00 & 26.20 & 2.42 & 0.44 & -.389 \\
Control & 30 & 12.00 & 25.00 & 19.33 & 3.84 & 0.70 & -.367 \\
\hline
\end{tabular}

Based on the data tabulated in Tables 1 and 2, the researchers concluded that the three groups performed differently on KET and the Concept Map post-test. While all groups performed similarly on KET, CCM group outperformed on the concept mapping with a higher mean score and better standard deviation index. The normality of ICM, CCM and Control group scores on KET and post test - for further decisions on the choice of parametric and non-parametric tests was investigated with the Kolmogorov-Smirnov test in SPSS 21. Accordingly, the assumption of Homogeneity of Variances in Levene's Test was sustained. To narrowly examine the hypothetical assumption on relative impact of ICM and CCM strategies on EFL learners' reading comprehension, a one-way ANOVA was run with the performance of Control, ICM and CCM groups on the concept mapping post-test.

Table 3. One-Way ANOVA: Post-test Scores

\begin{tabular}{|c|c|c|c|c|c|c|c|}
\hline & & & Sum of & $\mathrm{df}$ & Mean Sc & & Sig. \\
\hline & & (Combined) & 394.467 & 2 & 197.233 & 19.245 & .000 \\
\hline & Between & Linearity & 355.267 & 1 & 355.267 & 34.665 & .000 \\
\hline Post-Test * Groups & Groups & $\begin{array}{l}\text { Deviation from } \\
\text { Linearity }\end{array}$ & 39.200 & 1 & 39.200 & 3.825 & .054 \\
\hline & Within G & & 891.633 & 87 & 10.249 & & \\
\hline & Total & & 1286.100 & 89 & & & \\
\hline
\end{tabular}


As displayed in Table 3 , the index of $\mathrm{F}=19.245$ is significant at the $\mathrm{p}$-value $=.000$ for the Control, ICM and CCM groups. Therefore, it could be assumed that both individual concept mapping (ICM) and collaborative concept mapping (CCM) strategies improved the participants' reading comprehension during the treatment sessions in this study.

In order to testify the $\mathrm{H}_{0} 1$ and $\mathrm{H}_{0} 2$, the researchers tried to demonstrate that the individual and collaborative concept mapping strategies caused meaningful change in the performance of the participants on the post-test. The deviation of the ICM and CCM groups' performance from Control group could be examined with the significant F index in the test of ANOVA in Table 3. To measure the size of this impact, Eta Squared was calculated for scores on the Post-test. The measures of association are presented in Table 4.

Table 4. Effect Size: Post-test Scores

\begin{tabular}{lllll}
\hline & $\mathrm{R}$ & R Squared & Eta & Eta Squared \\
\hline $\begin{array}{l}\text { Post-test } * \\
\text { Groups }\end{array}$ & .526 & .276 & .554 & .307 \\
\hline
\end{tabular}

Table 4 displays the measure of $\operatorname{Eta}^{2}=.307$. To interpret this measure, a reference was made to Pierce et al (2004). Accordingly, it was concluded that the effect size of the ICM and CCM strategies on the participants' performance was large enough to enable the researchers to claim the meaningful impact of ICM and CCM strategies on Iranian EFL learners' reading comprehension. In order to investigate the relative difference between the reading performance of EFL learners who received ICM strategies from those who received CCM strategies nullified in $\mathrm{H}_{0} 3$, a multiple comparison was made among the KET and the post-test scores for Control, ICM and CCM groups by running a Scheffe Post Hoc test.

Table 5. Scheffe Post Hoc Test for Multiple Comparison of KET and ICM, CCM Post-test scores

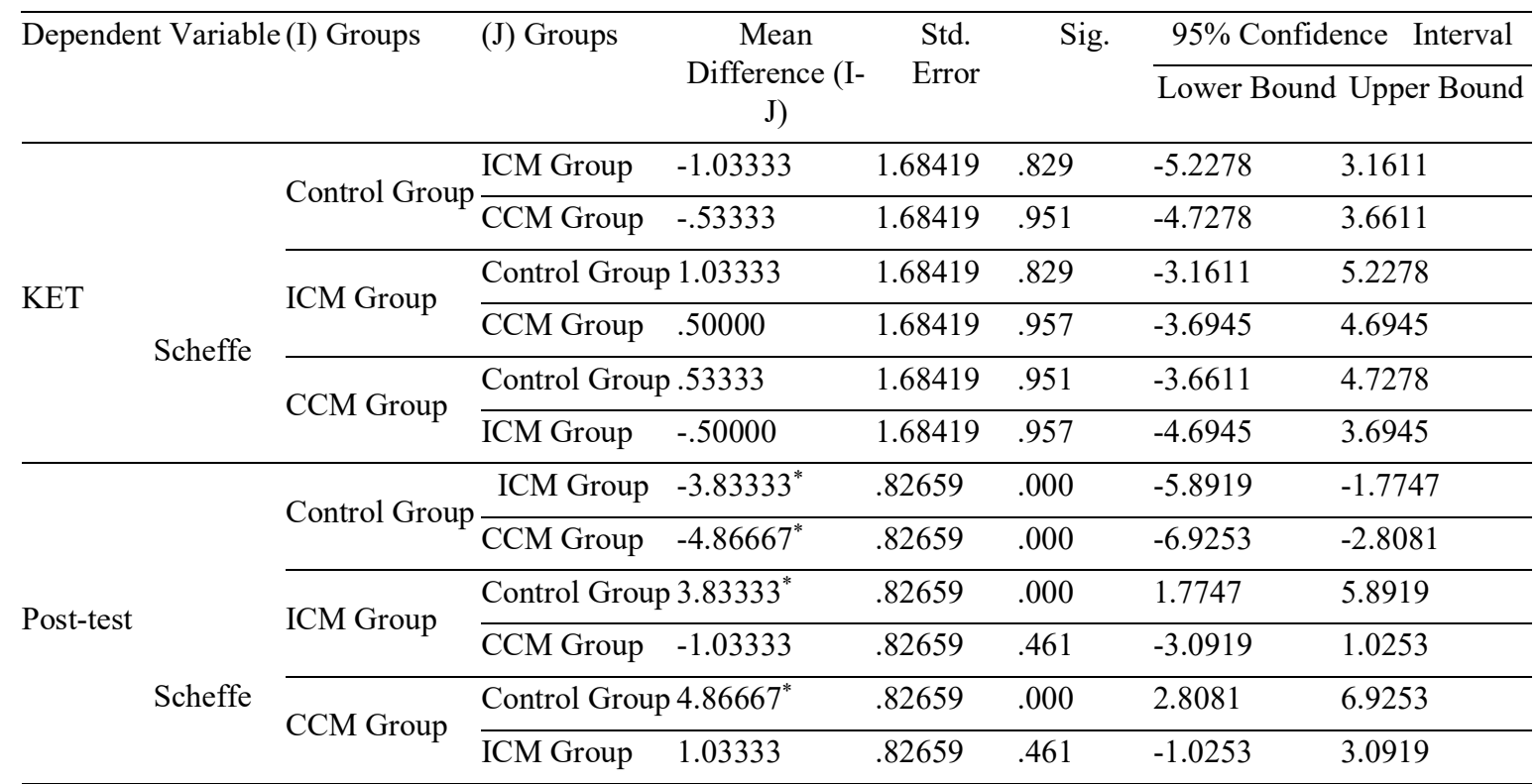

*. The mean difference is significant at the 0.05 level.

As Table 5 displays, the mean scores for the performance of Control, ICM and CCM groups were compared on KET and the concept mapping post-test, respectively.

\section{Multiple Comparison for KET Mean Scores}

- The mean scores for performance of Control (I) and ICM(J) groups on KET did not show any significant difference: $\mathrm{I}-\mathrm{J}=1.033$ at $\mathrm{p}$-value $=.829$.

- The mean scores for performance of Control (I) and CCM(J) groups on KET did not show any significant difference: $\mathrm{I}-\mathrm{J}=.533$ at $\mathrm{p}$-value $=.951$.

- The mean scores for performance of ICM (I) and CCM(J) groups on KET did not show any significant difference: I$\mathrm{J}=.500$ at $\mathrm{p}$-value $=.957$. 
Multiple Comparison for concept mapping post-test Mean Scores

- The mean scores for performance of Control (I) and $\operatorname{ICM}(\mathrm{J})$ groups on the post-test showed significant difference: I$\mathrm{J}=3.833$ at $\mathrm{p}$-value $=.000$

- The mean scores for performance of Control (I) and $\mathrm{CCM}(\mathrm{J})$ groups on the post-test showed significant difference: $\mathrm{I}-\mathrm{J}=4.866$ at $\mathrm{p}$-value $=.000$

- The mean scores for performance of ICM (I) and $\mathrm{CCM}(\mathrm{J})$ groups on the post-test showed no significant difference: $\mathrm{I}-\mathrm{J}=1.033$ at $\mathrm{p}$-value $=.461$

Referring to the data on Table 5, once more, the researchers confirmed no meaningful difference among the performance on KET by Control, ICM and CCM groups. However, their performance on the post-test had different patterns. While, the ICM and CCM groups showed different performance on the post-test from Control group, the ICM and CCM did not show a different performance. Therefore, relying upon the unexpected results in the post-test, the researchers were not able to reject the assumption of no meaningful difference between ICM and CCM groups on the post-test as expected in $\mathrm{H}_{0} 3$. Therefore, the $\mathrm{H}_{0} 3$ was sustained.

\section{Discussion}

The purpose of this study was to examine the relative impact of individual concept mapping (ICM) and collaborative concept mapping (CCM) strategies on EFL learners' reading comprehension. One possible cause for the positive impact of ICM strategy on learners' reading comprehension is that applying ICM strategy as a technique in reading comprehension coaches EFL learners to have an organized and well-structured information of the reading texts. ICM strategy enables the individuals to easily activate and energize their prior linguistic and world knowledge and to attempt connections between their prior knowledge and the new information they receive that eventually improves their bulk of declarative knowledge as successful foreign language learners (Skidmore 2008). ICM strategy can also serve as an instructional tool to promote individuals' conceptual understanding (Herl et al., 1999) and allows the learners to analyze structures, group ideas into categories, and get the main ideas of a text easily in order to understand the reading material (Novark \& Gowin, 1984). Accordingly, the researchers' accounts on the obtained results is indisputable in the sense that the positive impacts of ICM strategies on improving different aspects of EFL learners' performance have occasionally been supported in the literature.

On the other hand, the rejected $\mathrm{H}_{0} 2$ in this study supports the fact that collaborative concept mapping (CCM) strategy does have significant impacts on the participants' reading comprehension improvement. The CCM strategy helps students with lower achievement to understand the subject matter in their English classes and build up the active integration among the bits of their existing knowledge (Guastelio, Beasley \& Sinatra, 2000). When a collaborative concept map is generated by a working group and is shared with other students, it gives them a colorful pleasure of their reflective thoughts (Novak \& Gowin, 1999) and it can become an excellent process of building knowledge in a social environment that is cooperative and constructivist (Kumar 2012). Novak (2002) believed that concept maps are excellent tools for cooperative activity that leads to a very meaningful learning and combining cooperative learning with English reading instruction, creates for the students some opportunities to interact with peers, increases peer communication and support, encourages reading comprehension development, and lowers anxiety (Gillies \& Ashman, 2000). Collaborative concept mapping can become an excellent process of building knowledge in a social environment that is cooperative and constructivist (Kumar, 2012).

Referring to the unexpected results in the concept map post-test by both ICM and CCM groups in this study, the researchers speculated on the confounding effects of task involvement. They believed that the exciting experience the participants had with performing on concept maps was so intensive that their involvement overshadowed the effect of collaborative working or individual working on their performance. This assumption is consistent with the conclusion drawn by Skidmore (2008) wherein she was studying the effectiveness of concept mapping and collaborative groups in promoting understanding of ecology at the community college level. She listed some factors that interfered with the effect of collaborative concept mapping, such as (a) composition of the groups with respect to race, communicative competence and culture, (b) number of each group, (c) method of group assessment. The participants' group size was further studied by Esiobu and Soyibo (1995) wherein they reported that groups of five with mixed language and communicative abilities would work the best. Similarly, Slavin (1980) demonstrated that stating goals and objectives for the groups to direct all members to do well was significant to provide the greatest group benefits.

\section{Conclusion}

The results of this study further supported the positive effects of both individual and collaborative concept mapping strategies on EFL learners' reading comprehension in the Iranian context. The conventional method of having students read the English passages and answering the comprehension questions afterwards can become tedious to Iranian English learners. The concept mapping strategies have superiority over the traditional methods in performing reading comprehension tasks. Moreover, these strategies can be utilized as an assessment tool to evaluate reading comprehension ability, replacing the traditional reading comprehension questions (McClure et al., 1999).

The findings in present study recommend that the language teachers can incorporate ICM and CCMstrategies into their writing classes too. They can teach learners to write summaries out of the main ideas and concepts implied in passages they read in the pre-writing phase, understand the relationship among the concepts and develop the structured concept maps inside the texts that they are reading. Producing maps supervised by the teachers as a means to organize and 
elaborate course content can assist the language learners learn the texts more effectively, while they are acquiring concept mapping skills.

The individual and collaborative concept mapping strategies can be beneficial for EFL syllabus designers and material developers too. Considering the significant role that these strategies play on learners' reading comprehension, they can be considered as measuring tools for syllabus designers so that they can develop an educational framework to include lessons based on concept mapping strategies that facilitate reading comprehension skill.

\section{References}

Anderson, N. J. (1991). Individual differences in strategy use in second language reading and testing. Modern Language Journal, 75, pp. 460-472.

Boyle, T. (1997). Design for Multimedia Learning. Prentice Hall, London.

Broggy, J. (2009). What is Concept Mapping and how can it be introduced into a second level science classroom? Projects Officer in Teaching and Learning (Science) NCE-MSTL. Vol. 1(3), pp. 34-40.

Brown, A. L. (1987). Metacognition, executive control, self-regulation, and other more mysterious mechanisms. In F.E. Weinert\& R.H. Kluwe (Eds.), Metacognition, motivation, and understanding pp. 65-116. Hillsdale, NJ: Erlbaum.

Brown, D. (2007). Principles of language learning and teaching (5th ed.). NJ: Prentice Hall.

Bunner, T. L. (2002). Content area learning strategies to improve the learning of second language learners. Unpublished Master's project, California State University, Sacramento.

Carrell, P.L. (1983). Background knowledge in second language comprehension. Language learning and communication, (2), pp. 25-34.

Craik, F. I. M., \& Lockhart, R. S. (1972). Levels of processing: A framework for memory research. Journal of Verbal Learning and Verbal Behavior, (11), pp. 671-684.

Day, R. R., \& Bamford, J. (2002). Top ten principles for teaching extensive reading. Reading in a Foreign Language, (14), pp. 136-141.

Esiobu, G. O., \&Soyibo, K. (1995). Effects of concept and vee mappings under three learning modes on students' cognitive achievement in ecology and genetics. Journal of Research in Science Teaching, 32(9), pp. 971-995.

Eskey, D. E. (2005). Reading in a second language. In E. Hinkel (Ed.), Handbook of research on second language teaching and learning. Mahwah, NJ: Lawrence Erlbaum, pp. 563- 580.

Farhady, H. (2005). Reflections on and directions for ESP materials development in SAMT, in Kiani\&Khayamdar (Eds.) Proceedings of the First National ESP/EAP Conference, vol. 3 , Tehran, SAMT Publication.

Fraser, K. M. (1993). Theory Based use of concept mapping in organization development: Creating shared understanding as a basis for the cooperative design of work changes and changes in working relationships. (Doctoral dissertation). Cornell University.

Gao, H. (2007). The Effects of Key Concepts Availability and Individual Preparation in the form of Proposition Formation in Collaborative Concept Mapping on Learning, Problem Solving, and Learner Attitudes. Electronic Theses, Treatises and Dissertations.

Gao, H. (2013). Knowledge Construction in Collaborative Concept Mapping: A Case Study. Journal of Information Technology and Application in Education Vol. (2). pp. 78-89.

Guastello, E. F., Beasley, T. M., \& Sinatra, R. C. (2000). Concept mapping effects on science content comprehension of low-achieving inner-city seventh graders. Remedial and Special Education. pp. 356-365.

Herl, H. E., O'Neil, H. F., Chung, G. K. W. K., \&Schacter, J. (1999). Reliability and validity of a computer-based knowledge mapping system to measure content understanding. Computers in Human Behavior, 15(3/4), pp. $315-333$.

Hilbert, T. S., \&Renkl, A. (2008). Concept mapping as a follow-up strategy to learning from texts: What characterizes good and poor mappers? Instructional Science, (36), pp. 53-73. http://dx.doi.org/ 10.1007/s11251-007-9022-9

Horton, P.B., McConney, A. A., Gallo, M., Woods, A. L., Senn, G. J. \& Hamelin, D. (1993) 'An Investigation of the Effectiveness of Concept Mapping as an Instructional Tool', Science Education, 77(1), pp. 95-111.

Kumar, A. (2012). Does constructivist approach applicable through concept maps to achieve meaningful learning in Science? Asia-Pacific Forum on Science Learning and Teaching.

Liu, P. L., Chen, C. J., \& Chang, Y. J. (2010). Effects of a computer assisted concept mapping learning strategy on EFL college students' English reading comprehension. Computers \& Education, 54 (2010), pp. 436-445.

Mason, C. L. (1992). Concept mapping: a tool to develop reflective science instruction. Science Education, 76(1), pp. 51-56.

McClure, J. R., Sonak, B., \&Suen, H.K. (1999). Concept map assessment of classroom learning: Reliability, validity, and logistical practicality. Journal of Research in Science Teaching, (36), pp. 475-492.

Mintzes, J., Wandersee, J. and Novak, J. (1998). Teaching Science for Understanding. San Diego: Academic Press. 
Novak, J. D., \& Gowin, D. B. (1984). Learning how to learn. New York, NY: Cambridge University Press.

Novak, J. D. \& Gowin, D. B. (1999). Aprender an aprender. Lisboa: Plátano Edições Técnicas.

Novak, J. D. (2002). Meaningful learning: The essential factor for conceptual change in limited or appropriate propositional hierarchies (liphs) leading to empowerment of learners. Science Education, 86(4), pp. 548-571.

Novak, J. D., \& Canas, A. J. (2006). The theory underlying concept maps and how to construct them, [technical report IHMC Cmap Tools 2006-01]. Florida: Florida Institute for Human and Machine Cognition.

Nuttall, C. (1996). Teaching Reading Skills in a foreign language. Oxford: Heinemann.

Okebukola, P. A \& Ogunniyi, M. B (1984). Cooperative, competitive and individualistic laboratory interaction patterns: Effects on achievement and acquisition of practical skills. Journal of Research in Science Teaching, 22 (9), pp. 198-206.

O'Malley, J. M., Chamot, A. U., Stewner-Manzanares, G., Russo, R., \& Kupper, L. (1985). Learning strategy applications with students of English as a second language. TESOL Quarterly, 19, pp. 285-296.

Oxford, R. L. (1990) language learning strategies: what every teacher should know. New York, Newbury House.

Park, S. (1995). Implications of learning strategy research for designing computer-assisted instruction. Journal of Research on Computing in Education, 25 (4), pp. 435-456.

Pierce C.A., Block, C.A. \&Aguinis, H. (2004). Educational and Psychological Measurement 64(6).

Rashtchi, M. \& Keyvanfar, A. (2010). ELT: Quick' $n$ ' Easy. Tehran: Rahnama Press.

Rauch, S.J. \& Weinstein, A. B. (1968). Mastering Reading Skills. New York: D. Van Nostrand Company.

Shankar, P. (2008). Teaching of English. New Delhi: APH.

Shaw, H. (1959). Expository Reading for Writers. New York: Harper and Brothers Publishers.

Skidmore, L. (2008). Concept Mapping to Promote Meaningful Learning at the Community College Level. In L. Skidmore, Concept Mapping to Promote Meaningful Learning at the Community College Level (pp. 189).

Slavin, R. (1980). Cooperative learning. New York: Longman.

Van Boxtel, C., van der Linden, J. L., \&Kanselaar, G. (1997). Collaborative construction of conceptual understanding: interaction processes and learning outcomes emerging from a concept mapping and poster task. Journal ofInteractive Learning Research, 8 (3-4), pp. 341-361.

Van Boxtel, C., van der Linden, J. L., Roelofs, E., \&Erkens, G. (2002). Collaborative concept mapping: Provoking and supporting meaningful discourse. Theory into Practice, 41(1), pp. 40-46. http://dx.doi.org/10.1207/s15430421tip4101_7

Weinstein, C. E. (1988). Elaboration skills as a learning strategy. New York: Academic Press. 